\title{
Uma cidade em ruínas: representações literárias de Luanda em dois romances angolanos do pós-independência
}

\author{
Sheila Ribeiro Jacob \\ Universidade Federal Fluminense
}

\begin{abstract}
Resumo
Por meio da escrita literária da cidade de Luanda, é possível, ainda hoje, ler questionamentos e reflexões sobre os rumos tomados pelo próprio país, o que demonstra que, assim como no período da independência, a capital da nação permanece sendo representada como o duplo metonímico de Angola. É o que procuraremos demonstrar na leitura dos romances $O$ desejo de Kianda (1995), de Pepetela, e $O s$ transparentes (2012), de Ondjaki. Neles, desenha-se uma cidade em ruínas, onde os sonhos, tais como os prédios, desmoronam frente à corrosão dos valores e ao esquecimento dos ideais que, no passado, alimentaram o sonho de formação de um "homem novo".
\end{abstract}

Palavras-chave: Luanda; ruínas; romances angolanos; pós-independência.

\begin{abstract}
Through the literary writing of the city of Luanda, it is still possible to read questions and reflections about the course taken by the country itself. This affirmation demonstrates that, as in the period of independence, the nation's capital remains, in fiction, being represented as the double metonym of Angola. This is what we will try to demonstrate in reading the novels $O$ desejo de Kianda (1995), written by Pepetela, and Os transparentes (2012), written by Ondjaki. They show a ruined city, where dreams, like the buildings, collapse because of the values 'corrosion and the oblivion of ideals that, in the past, conceived the dream of forming a "new man".
\end{abstract}

Keywords: Luanda; ruins; Angolan novels; post-independence.

Recebido em: 31/03/19

Aprovado em: 20/06/19

Luanda é o nome resumido de um país, a imensa dimensão de uma cidade. Fernando Costa Andrade (1997, s/p.) 
Assim começa o clássico As cidades invisíveis, de Italo Calvino:

Não se sabe se Kublai Khan acredita em tudo o que diz Marco Polo quando este the descreve as cidades visitadas em suas missões diplomáticas, mas o imperador dos tártaros certamente continua a ouvir o jovem veneziano com a maior curiosidade do que a qualquer outro de seus enviados ou exploradores (1990, p. 9).

O encantamento do rei dos tártaros pelas sedutoras palavras com que Marco Polo apresenta cidades distantes dá o tom inicial dessa obra. Desde o início, portanto, somos sinalizados para o caráter ficcional e imaginativo que sustenta as descrições de territórios distantes pelo navegador veneziano. São espaços desconhecidos, cujos contornos se definem pelo trabalho criativo de alguém que, explicitamente, recusa a tentativa de objetividade para construir mapas imaginários, muito mais sedutores, inclusive, do que os tradicionais, como sinalizam os seguintes versos da poeta polonesa Wislawa Szymborska:

$[\ldots]$

Gosto dos mapas porque mentem.

Porque não dão acesso à verdade crua.

Porque magnânimos e bem-humorados

abrem-me na mesa um mundo

que não é deste mundo

(2016, p. 317).

O poema de Szymborska soma-se ao texto de Calvino e acaba por ressaltar a potência da escrita literária de cidades construídas no/pelo mundo da ficção. Nosso objetivo, neste artigo, é refletir sobre as representações da cidade de Luanda em textos publicados no pós-independência e que fazem da capital de Angola seu cenário privilegiado. Convocaremos, assim, algumas obras em que nosso "olhar percorre as ruas como se fossem páginas escritas", aqui citando, uma vez mais, Calvino (1990, p. 18).

\section{Luanda: cidade literária utópica}

A cidade de Luanda tem destacada presença na trajetória da literatura angolana. Durante um longo período, especialmente no tempo das lutas de libertação, Luanda foi palco de muitas das narrativas produzidas em Angola, podendo ser considerada, inclusive, como símbolo metonímico do país, como demonstram os versos do poeta angolano Costa Andrade, citados na epígrafe. É o que afirma a pesquisadora Tania Macêdo:

Mas Luanda, em sua multiplicidade, é, também, e talvez mesmo pelas contradições 
que a percorrem, a imagem símbolo de Angola. [...] Não causa espécie, portanto, que a cidade seja referência obrigatória no imaginário nacional e cenário privilegiado da literatura produzida no país. Dessa forma, cremos que estudar a literatura produzida em Angola é obrigatoriamente referir-se a Luanda, sua história e sua gente (2008, p. 14).

O escritor José Luandino Vieira é um dos principais nomes que nos vêm à mente quando pensamos em Luanda como espaço central da ficção angolana. Batizado José Vieira Mateus da Graça, nasceu em Portugal, mas, muito novo, foi para Angola, tendo vivido em Luanda, então capital da colônia, e desenvolvido um forte sentimento de identificação. O nome com que escolheu assinar suas obras e assumir-se em nova identidade ilumina a vinculação à cidade não de nascimento, mas de sua formação e amadurecimento.

Seu primeiro livro, A cidade e a infância, foi publicado em 1960 pela Coleção Autores Ultramarinos, da Casa dos Estudantes do Império (CEI). A obra demarca a potência da "cidade" desde o título e faz de Luanda a destinatária dos nove contos que ali se reúnem, destinatária esta grifada em maiúscula e em pé de igualdade e importância com os companheiros de infância. $\mathrm{O}$ espelhamento afetivo, sinalizado no título, reforça-se, assim, na dedicatória da obra, em que se lê:

\author{
Para ti \\ LUANDA \\ Para vocês \\ COMPANHEIROS DE INFANNCIA \\ (2007, s.p.)
}

O período em que esse livro foi editado pela CEI, ou seja, a passagem dos anos de 1950 aos de 1960, é marcado por tensões coloniais cada vez mais acirradas. Em 4 de fevereiro de 1961, data-chave na história da resistência angolana à dominação, teve início, oficialmente, uma ofensiva contra os colonizadores, com o famoso episódio do assalto às cadeias de Luanda. A literatura de então, fortemente vinculada à luta por autonomia, imprimiu os anseios de uma geração que ousava sonhar com uma nação autônoma, justa e igualitária. A cidade, como era literariamente representada, trazia a denúncia de uma situação de opressão e violência, mas também carregava a esperança de construção de uma ordem em diferença. Ainda segundo Macêdo, Luanda foi "ponto de convergência do 'desejo nacional", sendo, portanto, possível afirmar que "no período imediatamente anterior à independência, ela tornou-se símbolo de resistência ao colonialismo e luta pela liberdade" (MACÊDO, 2008, p. 32).

Nesse sentido, faz-se emblemático o conto "A fronteira de asfalto", publicado por José Luandino Vieira na referida coletânea $A$ cidade e a infância. Nele, há, ao mesmo tempo, a 
denúncia da violência, da opressão e dos contrastes físicos e simbólicos que faziam da cidade colonial uma cidade partida, como também o futuro representado pelas crianças Ricardo e Marina. A diferença de cor desses dois personagens não representava obstáculo algum para o convívio e as brincadeiras de quem ainda se encontrava inocente com relação aos preconceitos que eram fruto do e serviam ao acirramento a desigualdade social.

Além de Luandino Vieira, o escritor angolano Arnaldo Santos deve ser lembrado quando tratamos da produção literária que se fez em cumplicidade com a capital de Angola nos tempos da luta por libertação. Os dois escritores pertenceram ao mesmo grupo literário, a Geração Cultura. Em 1965, Arnaldo Santos publicou seu primeiro livro de contos, também com a chancela da Casa dos Estudantes do Império. Trata-se de Quinaxixe, cujo título faz referência à lagoa de mesmo nome que se tornou símbolo de Luanda e que foi aterrada, no início dos anos 1970, para a construção de um prédio, dando lugar ao Largo do Kinaxixi. Nesse caso, também, a vinculação com a cidade se faz explícita desde o título escolhido para batizar a obra.

Depois de conquistada a independência, a cidade de Luanda continuou sendo cenário privilegiado de boa parte da ficção angolana, mas sem os contornos de exaltação e afeto observados no passado. Mais uma vez, cabe convocar a avaliação de Tania Macêdo, para quem, nas novas representações da cidade,

se ausentam, explícitos, aqueles desejos de construção da nação presentes nos primeiros momentos da independência, ou o heroísmo de seus trabalhadores dos anos 60 e 70, para dar lugar a uma cidade em que se desenha o caos e, dessa maneira, emergem alguns de seus horrores e medos (2008, p. 196).

Dentre as muitas obras que exemplificam essa mudança de perspectiva, escolhemos para análise os romances $O$ desejo de Kianda (1995), de Pepetela, e Os transparentes (2012), de Ondjaki. Apesar de publicados em períodos distintos da história de Angola, é possível estabelecer um diálogo entre os dois. Em ambos, subvertem-se as representações literárias de Luanda que tomaram corpo no passado, apresentando-se, em contraste, a imagem de uma cidade em ruínas. Nela, os sonhos, tais como os prédios, desmoronam frente à corrosão dos valores e ao esquecimento dos ideais que no passado orientaram a formação do "homem novo".

$\mathrm{Na}$ leitura das duas obras, demonstra-se a falência do antigo projeto, mas, em vez de entregar-se à inevitabilidade do caos, a resistência teima em aparecer, tal como a flor que rompe o asfalto da cidade drummondiana cheia de tédio. Nesse sentido, concordamos com o pesquisador canadense Marc Brosseau, quando afirma que "em sua exploração dos diferentes aspectos da existência, o romance, como 'forma que busca', recorre ao espaço e aos lugares [...], e nessa busca também conhecemos algo de novo sobre o espaço e os lugares dos homens" (BROSSEAU, 2007, p. 79). Afinal, como lemos em Calvino, mais uma vez: "de uma cidade, não aproveitamos as suas sete ou setenta e sete maravilhas, mas a resposta que dá às nossas 
perguntas" (CALVINO, 1990, p. 44), como procuraremos demonstrar a seguir.

\section{Desmoronamento simbólico da cidade}

Tanto em $O$ desejo de Kianda quanto em Os transparentes, sinaliza-se, desde a primeira linha, a destruição de Luanda. No pacto inicial do leitor com os textos angolanos, aponta-se para o desmoronamento de prédios localizados na capital, como demonstra este trecho: "João Evangelista casou no dia em que caiu o primeiro prédio. No largo do Kinaxixi (PEPETELA, 1997, p. 7).

E este:

o Cego falou em direção à mão do miúdo que lhe segurava o corpo pelo braço, os dois num medo de estarem quietos para não serem engolidos pelas enormes línguas de fogo que saíam do chão a perseguir o céu de Luanda.

$[\ldots]$

a cidade ensanguentada, desde as suas raízes ao alto dos prédios, era forçada a inclinarse pra a morte (ONDJAKI, 2013, p. 9-11).

Em $O$ desejo de Kianda, uma série de prédios localizados na área central da cidade começa a desabar, sem, no entanto, penalizar seus moradores. Não tendo para onde ir, eles passam a ocupar o espaço público — a rua —, ao formar acampamentos improvisados. Já em Os transparentes, uma explosão faz a cidade inteira vir abaixo, inclusive o Prédio da Maianga, espaço central da narrativa, que "tinha sete andares e respirava como uma entidade viva" (ONDJAKI, 2013, p. 14). Nos dois casos, a partir da representação dos prédios, apresenta-se uma cidade em ruínas, o que, como saberemos conforme o avançar das narrativas, se deve à corrosão de valores e ao desmoronamento dos sonhos que, um dia, embalaram os habitantes de Luanda e os escritores que se dedicaram a cantá-la em sua ficção.

Nas duas obras, a cidade é representada como terreno das desigualdades, dos vícios e do abandono de valores éticos e morais. Vemos como os "condenados da terra", assim referidos por Frantz Fanon em 1961 quando tratou das vítimas da colonização, deram lugar aos "condenados da cidade" (2001) a que Löic Wacquant (2017) faz referência quando trata dos habitantes de "comunidades estigmatizadas [...] nas quais os párias urbanos residem e onde os problemas sociais se congregam e infeccionam" (p. 7). Apesar de se passarem em tempos históricos distintos - O desejo de Kianda se passa em meio à guerra civil e Os transparentes já no pós-2002, ou seja, depois de a guerra civil ter sido oficialmente extinta - , os adjetivos que identificam a cidade nos dois textos corroboram a escrita de uma "cidade do caos" a que Tania Macêdo fez referência, onde a paz decretada não conseguiu dirimir os problemas históricos que ali ainda persistem.

Em $O$ desejo de Kianda, apresenta-se uma Luanda em que o direito à habitação não é 
garantido. "Havia tanta falta de residências na cidade que nenhuma autoridade teve coragem de ir desalojar as pessoas. Atirá-las para onde?” (PEPETELA, 1997, p. 34). Em Os transparentes, a cidade é "caótica" (ONDJAKI, 2013, p. 22), "demasiado cara" (p. 24), onde mansões, carros de luxo e roupas de grife convivem, lado a lado, com a miséria e a falta de moradia.

Nos dois casos, observa-se uma Luanda das desigualdades, dos contrastes, das fronteiras simbólicas que existiam no tempo colonial e permanecem nos dias atuais. Lá, por exemplo, havia "os carros dos novos ricos, últimos modelos de vidros fumados e ar condicionado, para proteger os passageiros dos pedidos constantes de esmola por parte dos meninos de rua, dos mutilados de todas as guerras, dos velhos atirados para a rua pela nova mendicidade" (PEPETELA, 1997, p. 95).

Também em Os transparentes, um ministro, "trajando um fato caro, uma fina gravata de seda e sapatos comprados em Paris" (ONDJAKI, 2013, p. 33) contrastava com a penúria e as dificuldades por que passavam os moradores do Prédio da Maianga. Encastelado em seu escritório, ignora que "falta água em Luanda, demasiadas vezes, o abastecimento está completamente irregular (ONDJAKI, 2013, p. 93). Nessa cidade desigual é possível haver, de um lado, uma mansão governada por uma madame "repleta de ouro desde os dedos dos pés às orelhas" (ONDJAKI, 2013, p. 62). De outro, vivendo e sobrevivendo nas/das ruas, personagens como o Vendedor de Conchas e o Cego. Ou seja: "Luanda fervia com a sua gente que vendia, que comprava para vender, que se vendia para depois ir comprar e gente que se vendia sem voltar a conseguir comprar" (ONDJAKI, 2013, p. 67).

Como já afirmamos, é possível ler o desmoronamento dos prédios como um símbolo da ruína dos sonhos e dos projetos de antigamente, de um tempo em que se lutava contra os invasores estrangeiros e se acreditava em um novo porvir. No caso de $O$ desejo de Kianda, essa transformação ética se personifica nos valores que passam a orientar as atitudes de CCC, sigla que identifica Carmina Cara de $\mathrm{Cu}$, esposa de João Evangelista. Jovem idealista e revolucionária no passado, antiga combatente pela liberdade e pelo socialismo, no presente da narrativa ela já se entregou à corrupção, ao individualismo e ao enriquecimento ilícito. Ela comprova o que Frantz Fanon havia previsto quanto à atuação das burguesias nacionais de países colonizados após a tomada do poder: "Cada vez mais a burguesia nacional vira as costas ao interior, às realidades do país em abandono e olha para a antiga metrópole, para os capitalistas estrangeiros que fornecem os seus serviços" (2005, p. 195).

E continua:

O camponês que continua a cavoucar a terra, o desempregado que nunca encontra emprego não conseguem convencer-se, apesar das festas, apesar das bandeiras - no entanto novas - de que algo mudou de verdade em suas vidas. A burguesia no poder multiplica inutilmente as demonstrações, as massas não conseguem se iludir. As massas têm fome e os delegados de polícia, hoje africanos, não as tranquilizam muito (2005, p. 199). 
Os tempos são outros, mas as práticas e as vontades continuam as mesmas. Com o decorrer da narrativa, percebemos ter razão João Evangelista, quando questiona a esposa: “já esqueceste as lições antigas?” (PEPETELA, 1997, p. 53). Apesar da resposta afirmativa que deveria vir à pergunta, sabemos que, no entanto, não foi só Carmina quem abandonou os saberes de outros tempos: também os moradores da cidade estavam entregues à surdez e ao esquecimento, e por isso mesmo a área central de Luanda fora condenada a ruir. O mais-velho Mateus Evangelista, em conversa com o filho, afirma:

Isto tudo está relacionado com a falta de Fé dos angolanos. Hoje vivemos numa sociedade de pedintes e ladrões. Onde estão os valores morais que impediam as invejas, os ódios, os actos arbitrários, os ajustes de conta, a ganância? Desapareceram (PEPETELA, 1997, p. 103).

Já em Os transparentes, a entrega dos bens naturais às multinacionais, levando à privatização da água e à exploração do petróleo pela Comissão Instaladora do Petróleo Encontrável em Luanda (CIPEL), é o que acaba resultando na explosão de Luanda, pois as escavações da cidade foram feitas de forma descuidada. $\mathrm{O}$ anúncio havia sido feito pelo engenheiro angolano Davide Airosa: "não há como a cidade aguentar, nem é possível tirar o petróleo que há embaixo de Luanda. É simplesmente não concretizável” (ONDJAKI, 2013, p. 117). No entanto, seu alerta fora ignorado.

Com essas transações observadas em Luanda, que levariam à destruição da capital, mantém-se a lógica do colonialismo, já agora com novas roupagens, pois quem, no presente da narrativa, protagoniza a entrega dos recursos africanos são os próprios filhos do país em sujas e imorais negociatas. Por meio da destruição simbólica da capital representa-se o saque do país - e do continente - como um todo. Na leitura de Joseph Ki-Zherbo, há hoje, como na aurora da colonização, um verdadeiro assalto aos recursos naturais africanos: "Assim, hoje, há um novo tipo de partilha da África que não confessa o seu nome, mas que se faz através da invasão capitalista, sobretudo financeira, nas diferentes zonas do continente" (KI-ZHERBO, 2009, p. 46).

$\mathrm{Na}$ fala do personagem Esquerdista, em Os transparentes, lê-se a denúncia dos valores neocoloniais que reinam soberanos e a surdez quanto aos valores tradicionais representados por Kianda:

durmam enquanto vos anestesiam com doses de suposta modernidade!, é carros lindos, é internetes que nem funcionam, é marginal nova com prédios construídos em areias dragadas sem pedir licença à Kianda, é furar o corpo da cidade sem querer ouvir os outros que já furaram o corpo da cidade deles, onde não deu certo... ouçam bem, dorminhocos, lá não deu certo, e aqui, porque somos estúpidos, cegos e coniventes, 
isto é, porque somos globalmente corruptos, aqui a cidade vai ser furada, a água vai ser privatizada, o petróleo vai ser sugado sob nossas casas, os nossos narizes, e as nossas dignidades... (ONDJAKI, 2013, p. 237).

Assim como Carmina Cara de $\mathrm{Cu}$, em $O$ desejo de Kianda, personaliza a transformação dos antigos sonhos em novos projetos de exploração e enriquecimento, há um momento em que a Luanda de Os transparentes para e vive seu luto porque morreu a Ideologia:

invadida por um torpor, com exceção dos trabalhadores cipelinos, a cidade parecia evacuada, o silêncio nas casas era interrompido pelos rádios ou aparelhagens tristes, as crianças pareciam inibidas nas suas vontades de brincar, os cães encheram os olhos de uma tristeza mais aguda em homenagem ao falecimento prematuro da senhora Ideologia (ONDJAKI, 2013, p. 318).

A perda dos valores éticos e morais de antigamente leva à ruína não só dessa cidade-país, mas também ao próprio esmorecimento da utopia que embalou a escrita de Luanda no passado.

\section{O fim das representações literárias antigas}

Um dos principais personagens de Os transparentes é Odonato, um mais-velho que vai perdendo a cor até ficar translúcido, servindo, assim, de inspiração para o título da narrativa de Ondjaki. Ele sente saudade de uma Luanda que, física e simbolicamente, já não existe, cidade que, no passado, apesar das carências, da miséria e do atraso, ainda pulsava de afeto e alegria:

Luanda era então, se comparada com a atualidade, um quase deserto urbano onde faltava a comida e a roupa, os medicamentos, sem água ou luz, muitas vezes faltava cerveja ou vinho [...] não havia linhas telefónicas estáveis mas as conversas eram abençoadas pelos tardios ventos da madrugada, os sapatos estavam gastos mas as pernas felizes num contentamento de incontáveis noites de kizomba, havia o recolher obrigatório e por isso mesmo as festas se enchiam de uma gente que a garantia em sorrisos e animação até depois das cinco da manhã [...] nasciam então tantas crianças, morriam outras tantas, nasciam outras mais, as festas pobres serviam mais para rever familiares e vizinhos do que para comer ou cometer exibicionismos de novo riquismo, o mar era mais generoso em peixe

E até as pessoas eram mais brandas,

$[\ldots]$

(ONDJAKI, 2013, p. 168).

Essa Luanda que desperta nostalgia em Odonato fora cantada, como vimos, por nomes como Luandino Vieira — autor de Luuanda (1963) e Nós os do Makulusu (1977) — e Arnaldo Santos - cujo primeiro livro em prosa foi, como dissemos, Quinaxixe (1965). É o próprio romance que destaca: 
Odonato viu-se de peito revolto a sentir claras saudades de uma Luanda que ali havia sem já haver, talvez o tempo se sobrepunha para o fazer sofrer, os pássaros de um antigo Kinaxixi com trejeitos de Makulusu cantavam invisíveis no seu ouvido semitransparente,

era ele que falava com a cidade ou era a cidade de Loanda, Luanda, Luuanda que brincava de namorar com ele? (ONDJAKI, 2013, p. 170).

Como grandes sabedores e admiradores, no passado, "das coisas de Luanda", Luandino e Arnaldo Santos também são referidos no romance de Pepetela, sendo convocados como personagens no momento em que João Evangelista se recorda de uma conversa travada décadas antes, perto do mercado do Kinaxixi:

Ali perto devia ser o sítio onde há trinta e tal anos [sic] derrubaram a mafumeira de Kianda, quando construíram a praça. Toda aquela zona fora uma lagoa e havia uma mafumeira que foi cortada e chorou sangue pelo cepo durante uma semana. Ouviu a estória um dia, ali mesmo numa esplanada, quando se sentou com o maior respeito à mesa onde se encontravam dois escritores, Luandino Vieira e Arnaldo Santos, grandes sabedores das coisas de Luanda. Como não podia deixar de ser, os kotas falavam de sua meninice kinaxixense, embora Luandino fosse do Maculusso, que de facto era ali ao lado (PEPETELA, 1997, p. 46, grifo nosso).

Nos dois romances, faz-se referência, portanto, à imagem literária utópica de Luanda cujos contornos foram definidos, principalmente, por escritores como Luandino Vieira e Arnaldo Santos, por esse motivo referidos, direta ou indiretamente, nos dois textos. A cidade foi, naquele período, cantada como o "lugar" do afeto, conforme definido por Marcelo Lopes de Souza. Segundo esse pesquisador, para os geógrafos, quando se trata de "lugar",

nãoé a dimensão do poder que está em primeiro plano ou que é aquela mais imediatamente perceptível, diferentemente do que se passa com o conceito de território; mas sim a dimensão cultural-simbólica e, a partir daí, as questões envolvendo as identidades, a intersubjetividade e as trocas simbólicas, por trás da construção de imagens e sentidos dos lugares enquanto espacialidades vividas e percebidas, dotadas de significado [...] Por conseguinte, como já tive ocasião de chamar a atenção do leitor ou leitora em momentos anteriores, ainda que com outras palavras, o lugar está para a dimensão cultural-simbólica assim como o território está para a dimensão política (SOUZA, 2013, p. 115, grifo do autor).

Nas representações ficcionais de Luanda, especialmente as feitas no passado, privilegiavam-se as identidades, a intersubjetividade e as trocas simbólicas que se davam naquele "lugar" onde o sonho era possível. Na atualidade, a realidade se apresenta de forma muito mais complexa e instigante. Percebeu-se que, como havia afirmado Ki-zerbo, "a revolução é 
o inverso do existente. É não só virar a página, mas mudar de dicionário” (KI-ZERBO, 2009, p. 19). Ainda que parte da literatura angolana de hoje, como as duas obras aqui convocadas, permaneça denunciando as dificuldades de se mudar de dicionário, ainda é possível enxergar caminhos para a construção do inverso do existente.

\section{Ainda há lugar para o sonho em Luanda?}

O pesquisador Renato Cordeiro Gomes, ao fazer referência às "Seis propostas para o próximo milênio", de Italo Calvino, lembra que, na definição do escritor italiano, "a cidade é o símbolo capaz de exprimir a tensão entre racionalidade geométrica e o emaranhado das existências humanas" (GOMES, 1994, p. 23). É como esse terreno dos excessos, das contradições, da dureza do asfalto e da leveza das vidas que Luanda nos é representada. Mesmo que a cidade utópica do passado se represente em ruínas, em ambos os textos ainda é possível ler que, teimosamente, os sonhos ainda resistem, mesmo em meio aos escombros.

Em $O$ desejo de Kianda, para tentar encontrar explicações para a queda dos prédios recorre-se a cientistas, pastores, sismólogos americanos, uma equipe multidisciplinar francesa... Todo o arcabouço epistemológico do Ocidente é, de imediato, valorizado e requisitado. No entanto, a resposta encontrava-se ali mesmo, na própria cidade, gritando sua presença no largo do Kinaxixi, mas sendo ignorada pelos transeuntes, surdos aos apelos da tradição. Bastava estar atento às vozes do passado para identificar a reclamação de Kianda, aprisionada sob o solo da lagoa aterrada. Um dia isso muda: "Era um cântico suave, doloroso, que uma criança um dia ouviu" (PEPETELA, 1997, p. 55).

Mesmo desacreditada pelos amigos, a menina Cassandra não deixa de prestar atenção à mensagem que aquela divindade das águas queria transmitir. No entanto, assim como a personagem de mesmo nome da mitologia grega, ninguém prestava atenção ao que ela dizia. Só quem lhe dá confiança é o "mais velho Kalumbo, cego e desdentado" (PEPETELA, 1997, p. 98), que sabe que o espírito das águas se manifesta de diversas formas e tinha muitos motivos para querer externar sua insatisfação:

enquanto no prédio em construção Cassandra contava para velho Kalumbo a letra completa da canção que finalmente conseguira perceber. Se tratava dum lamento de Kianda, como já tinham previsto anteriormente, que queixava de ter vivido durante séculos em perfeita felicidade na sua lagoa, até que os homens resolveram aterrar a lagoa e puseram cimento e terra e alcatrão por cima, construíram o largo e os edificios todos à volta. Kianda se sentia abafar, com todo aquele peso em cima, não conseguia nadar, e finalmente se revoltou. E cantou, cantou, até que os prédios caíssem todos, um a um, devagarinho, era esse o desejo de Kianda. E foi isso que Cassandra contou ao mais velho Kalumbo (PEPETELA, 1997, p. 109, grifos do autor). 
Demonstra-se, assim, que o velho e o novo, juntos, é que poderão contribuir para a construção de um futuro em diferença. É preciso andar para a frente, mas sem deixar de ouvir as lições e os apelos da tradição. Além disso, em $O$ desejo de Kianda vemos que novas formas de organização começam a despontar, deixando de lado a hierarquização e autoridade dos partidos tradicionais para apostar na horizontalidade e na pluralidade de vozes e opiniões. Trata-se do movimento dos desalojados nus do Kinaxixi, uma forma de protesto "divertida", "coletivista" e "solidária", na avaliação de Honório, amigo de João Evangelista (PEPETELA, 1997, p. 113).

Em Os transparentes, o apreço ao coletivo e as relações de cumplicidade dos moradores do Prédio da Maianga também se opõem ao individualismo e ao egoísmo reinantes do lado de fora: "o prédio tinha este dom de acolher quem entendesse dever acolher, banharam-se como se fossem os últimos cidadãos do mundo" (ONDJAKI, 2013, p. 173). Seus moradores elaboraram, inclusive, um esquema coletivo e improvisado de segurança. Por meio do Prédio da Maianga é possível conhecer uma Luanda que, apesar do descaso, ainda vibra na beleza das pessoas, como afirma Xilisbaba: "o que é bonito nesta cidade, Odonato... são as pessoas. as festas, o ritmo, até os enterros" (ONDJAKI, 2013, p. 48).

É, portanto, na beleza das pessoas que não se entregam à ganância nem aos apelos do egoísmo e individualismo que a cidade ainda encontra suas possibilidades de resistência.

Assim como identificou Renato Cordeiro Gomes nas representações literárias da cidade do Rio de Janeiro, podemos afirmar que, também nas obras ora convocadas para uma breve análise, há uma "simultaneidade contraditória de entusiasmo e ironia, de envolvimento afetivo e de crítica" (GOMES, 1994, p. 31) na abordagem apresentada de Luanda. Na geografia literária da capital de Angola hoje convivem a desordem, a desigualdade e a violência, mas também os desejos, os afetos e variadas formas de sobrevivência. São, enfim, várias cidades em uma só.

\section{Referências}

ANDRADE, Fernando Costa. Luanda: poemas em movimento marítimo. Luanda: Executive Center, 1997.

BROSSEAU, Marc. O romance: outro sujeito para a geografia. Trad. Márcia Trigueiro. In CORREAA, Roberto Lobato; ROSENDAHL, Zeny (Orgs.) Literatura, música e espaço. Rio de Janeiro: EdUERJ, 2007. p. 79-122

CALVINO, Italo. As cidades invisiveis. Trad. Diogo Mainardi. São Paulo: Companhia das Letras, 1990.

FANON, Frantz. Os condenados da terra. Trad. Enilce Albergaria Rocha e Lucy Magalhães. Juiz de Fora: Editora UFJF, 2005.

GOMES, Renato Cordeiro. Todas as cidades, a cidade. Rio de Janeiro: Rocco, 1994.

KI-ZERBO, Joseph. Para quando a África?: entrevista com René Holenstein. Trad. Carlos Aboim de Brito. Rio de Janeiro: Pallas, 2009. 
MACÊDO, Tania. Luanda, cidade e literatura. São Paulo: Editora da Unesp, 2008.

ONDJAKI. Os transparentes. São Paulo: Companhia das Letras, 2013.

PEPETELA. O desejo de Kianda. Lisboa: Dom Quixote, 1997.

SOUZA, Marcelo José Lopes de. Os conceitos fundamentais da pesquisa socioespacial. Rio de Janeiro: Bertrand Brasil, 2013.

SZYMBORSKA, Wislawa. Um amor feliz. Trad. Regina Przybycien. São Paulo: Companhia das Letras, 2016.

VIEIRA, José Luandino. A cidade e a infância. São Paulo: Companhia das Letras, 2007.

WACQUANT, Löic. Os condenados da cidade: estudo sobre marginalidade avançada. Trad. João Roberto Martins Filho et al. Rio de Janeiro: Revan; FASE, 2017.

\section{Minicurrículo}

Sheila Ribeiro Jacob é professora do Colégio Pedro II e doutoranda em Literatura Comparada pela Universidade Federal Fluminense. 